\title{
CALIPSO Recordings and Categorization of Atmospheric Aerosols over the Urmia Lake
}

\author{
Fatemeh Ghomashi ${ }^{1, *}$ and Hamid R. Khalesifard ${ }^{1,2, * *}$ \\ ${ }^{1}$ Department of Physics, Institute for Advanced Studies in Basic Sciences, No. 444 Prof. Sobouti Blvd., Zanjan 4513766731, Iran \\ ${ }^{2}$ Center for Research in Climate Change and Global warming, Institute for Advanced Studies in Basic Sciences, No. 444 Prof. Sobouti \\ Blvd., Zanjan 4513766731, Iran
}

\begin{abstract}
The Urmia Lake is suffering from a severe drought scenario that started in recent decades. The lake has lost almost $88 \%$ of its surface area in comparison to its value in 1995. This has left a bed of salt around the lake, that has the potential to disperse a significant amount of aerosols (dust and salt) into the atmosphere. We use the recordings of the CALIPSO satellite to investigate the optical parameters of atmospheric aerosols over the Urmia Lake. For this purpose, the aerosol optical depth (AOD) and the particulate depolarization ratio (PDR) at $532 \mathrm{~nm}$ have been selected from the whole available recordings of the CALIPSO. To distinguish between the atmospheric particles which are originating from the lake bed and those that are transported from the surrounding sources to the lake area, the PDR has been categorized for two altitude ranges, i.e., from the ground level up to $2 \mathrm{~km}$ above the mean sea level (amsl) and above $3 \mathrm{~km}$ amsl. Investigating the variations of the PDR at these two altitude ranges, provides information about the type of atmospheric particles at different times of the year. Although it is not easy to distinguish between the transported dust layers and atmospheric particles from the lake bed, it seems that the Urmia Lake is mostly active in the driest times of the year, i.e., June to October. Also, it seems that the particles which are originating from the lake, are mostly dry salt particles, where their corresponding PDR is $0.16 \pm 0.05$.
\end{abstract}

\section{Introduction}

The Urmia Lake (UL) in Northwest Iran $\left(37.62^{\circ} \mathrm{N}\right.$, $45.41^{\circ} \mathrm{E}$ ) is one of the most hypersaline lakes in the world [1]. The UL is located in a semi-arid region and its basin is surrounded by mountainous lands with several vast plains in the valleys and around the lake. The elevation of the UL water catchment is changing from $1260 \mathrm{~m}$ above the mean sea level (amsl) at the deepest point of the lake bed up to $3710 \mathrm{~m}$ at Sahand mountains [2]. In recent decades, the UL has experienced a serious drying challenge. The average water level of the lake has been dropped significantly and in such a way that its surface area has been shrunk to just $12 \%$ of its value in 1995 [3]. Many reasons have been mentioned for the drought of the lake, including climate change $[4,5]$ and human factors like building dams, digging too many wells and excessive use of water resources in the catchment area of the lake for agricultural irrigation [3, 6-8]. Dry up of the UL has turned it to an active source of salt particles which has given it the potential to produce salt storms when strong winds are blowing over the lake [9]. In addition, neighboring dust sources like the Mesopotamia and Syrian desert and even the Turkmenistan region have considerable impacts on Northwest Iran [10-13] as well as the UL region. Also it is expected that large cities and different industries inside

\footnotetext{
*e-mail: f.ghomashi@iasbs.ac.ir

**e-mail: khalesi@iasbs.ac.ir
}

the water catchment region of the lake, produce considerable amounts of urban-industrial particles. The existence of such type of particles is impacting on the atmospheric horizontal visibility during the cold months of the year when atmospheric inversion is happening. In this work, we use the level 2 products of the Cloud-Aerosol Lidar and Infrared Pathfinder Satellite Observations (CALIPSO) to investigate the optical parameters of atmospheric aerosols over the lake and its surroundings. For this purpose, columnar aerosol optical depth (AOD) and columnar particulate depolarization ratio (PDR) at $532 \mathrm{~nm}$, have been selected from the whole available data set. To distinguish between the particles which are originating from the lake bed, transported dust particles and other local atmospheric aerosols, the PDR has been monitored at two different altitude ranges, which are dictated by the orography of the region. The variations of the PDR at these two ranges in comparison to each other provide information about the type of particles that are emitted by the lake as well as its seasonal activities as a source of atmospheric aerosols.

\section{The investigated area, data set and methodology}

Fig. 1 shows an orography map of the investigated region. It should be noted that the considerable large cities like Urmia (>750,000 inhabitants) and Tabriz (>1.5 million inhabitants) and few smaller ones like Maragheh, Salmas 


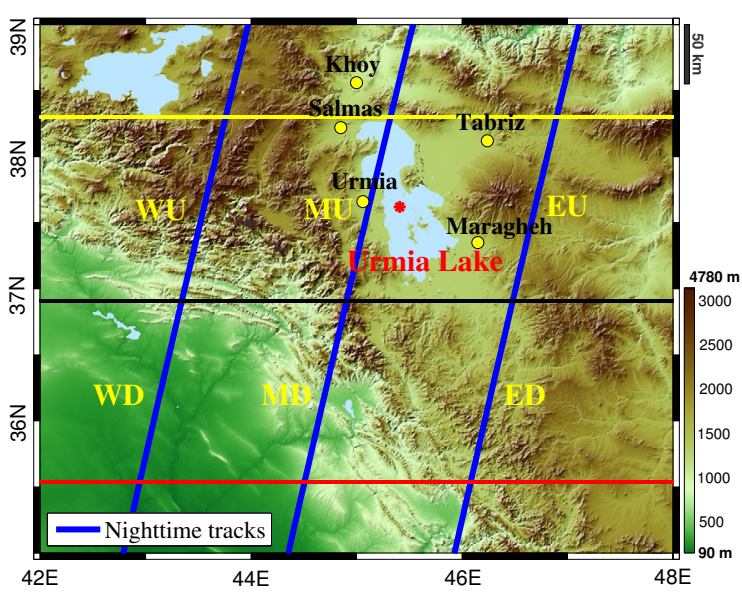

Figure 1. CALIPSO nighttime ground tracks over the Urmia Lake region. M, is partly passing over the UL, and W (E) from its west (east) side. Parts of the tracks between the black and yellow (red) lines are labeled with U (D).

and Khoy are inside the water catchment area of the lake. Different industries of different sizes are also active in this region. The lake region is also under the influence of neighboring dust sources like the Tigris and Euphrates basin $[10,11]$. Therefore it is expected that dust, salt and anthropogenic particles would contaminate the atmosphere in this region. Fig. 1 also depicts segments of three nighttime CALIPSO ground tracks. For simplification, the middle track that is partly passing over the UL is labeled by $\mathrm{M}$ and the one that is passing from its east (west) side is labeled with $\mathrm{E}(\mathrm{W})$. To study the effect of the lake over the atmospheric particles in the region each track has been divided into two parts, up, $\mathrm{U}$, and down, $\mathrm{D}$, where $\mathrm{U}$ (D) is corresponding to the region between the black and yellow (red) lines in Fig. 1. The CALIPSO level 2 aerosol products have been used to extract AOD and PDR for the mentioned track segments (WU, MU, EU, WD, MD, and ED) during June 2006 to December 2017. The AOD is a measure of the extinction of light by particles in a column of air and is determined by the columnar integration of extinction coefficient $\sigma_{a}(z)$ over the atmospheric column, where CALIPSO is measuring from the top of the atmosphere, $z_{\text {top }}$, down to the ground level, $z_{\text {base }}$ [14],

$$
\mathrm{AOD}=\int_{z_{\text {top }}}^{z_{\text {base }}} \sigma_{a}(z) d z
$$

AOD has been calculated and averaged along each of the 6 segments (Fig. 1) for all cloud free overpasses of the satellite for the whole data set.

$\operatorname{PDR}(\delta)$ is defined as ratio of the layer integrated perpendicular to parallel polarization components of particulate backscatter coefficients at a given altitude $z$ [15],

$$
\delta=\frac{\beta_{\perp, p}(z)}{\beta_{\|, p}(z)}
$$

Here $\beta_{\perp, p}$ and $\beta_{\|, p}$ are perpendicular and parallel components of the particulate backscatter coefficient at 532 $\mathrm{nm}$, respectively.

Since the crest lines of the mountains which are surrounding the UL are $\sim 3000 \mathrm{~m}$ amsl, to distinguish between the transported dust particles to the region and the particles which are originating from the local sources including the lake, $\delta$ has been calculated for two altitude ranges. For the ground track $\mathrm{MU}, \delta_{\mathrm{l}}\left(\delta_{\mathrm{h}}\right)$ corresponds to averaged PDR over the track segment for altitudes from the ground level up to $2 \mathrm{~km}$ (higher than $3 \mathrm{~km}$ ) amsl.

\section{Results and discussion}

The seasonal average of AOD at $532 \mathrm{~nm}$ for segments WU, MU and EU (WD, MD, and ED) are shown in Fig. 2a (2b). Looking at Figs. $2 \mathrm{a}$ and $2 \mathrm{~b}$ one can find that almost during the whole length of the year, the AOD is higher in the regions in the south of the lake which are out of the water catchment region. Comparing this result with previous works $[9-13,16]$ it can be concluded that dust outbreaks which are originating from sources in the west side of the lake, like the Mesopotamia, Syrian desert and even African sources and those which are located on its east side are impacting the whole area. Lower values of AOD in the UL water catchment region can be due to the act of high altitude mountains as barriers to dust layers around the lake. Fig. 2a also shows that for almost all times of the year the atmosphere above the UL is experiencing higher values of aerosol loadings in comparison to its west and east sides especially in the driest seasons of the year, i.e., summer and autumn. From this behavior, one can conclude that the lake is a substantial atmospheric particle source in this region.

Fig. 3 displays the variations of $\delta_{1}$ versus $\delta_{\mathrm{h}}$ for the whole available data subject to the condition $\tau_{a}>0.04$. Fig. 3a shows that most of the aerosol loadings into the atmosphere happen from June to October but there are many cases where $\delta_{1}$ and $\delta_{\mathrm{h}}$ are different from 0.27 to 0.35 corresponding to the depolarization ratio for clean dust [17]. It has been already reported that depolarized lidar signals from dry salt particles have $\delta \sim 0.15$ [18]. For few cases $\delta_{1}$ $>\delta_{\mathrm{h}}$ and at the same time $0.15<\delta_{\mathrm{l}}<2$. It is expected that such cases would correspond to particle loading from the lake bed into the atmosphere which the CALIPSO algorithm takes them as polluted dust [19, 20]. To detect such cases, we looked at all CALIPSO time series were showing a dust plum in contact with the lake bed subject to the condition that $0.1<\delta_{1}<0.25$ to eliminate dust and urban industrial particles. The blue dots in Fig. $3 \mathrm{~b}$ are results of such calculations. Yellow and black circles in Fig. 3b are corresponding to dust events and urban-industrial particles respectively. Considering the blue circles that have been shown in Fig. 3b, one can find that $\delta_{1}=0.16 \pm 0.05$. It should be mentioned that for most cases it is not easy to distinguish between the particles from the lake bed and dust layers which have been transported high above the mountains and reached the UL basin.

Fig. 4 is a typical CALIPSO total attenuated backscattering time series at $532 \mathrm{~nm}$. Its corresponding event is 

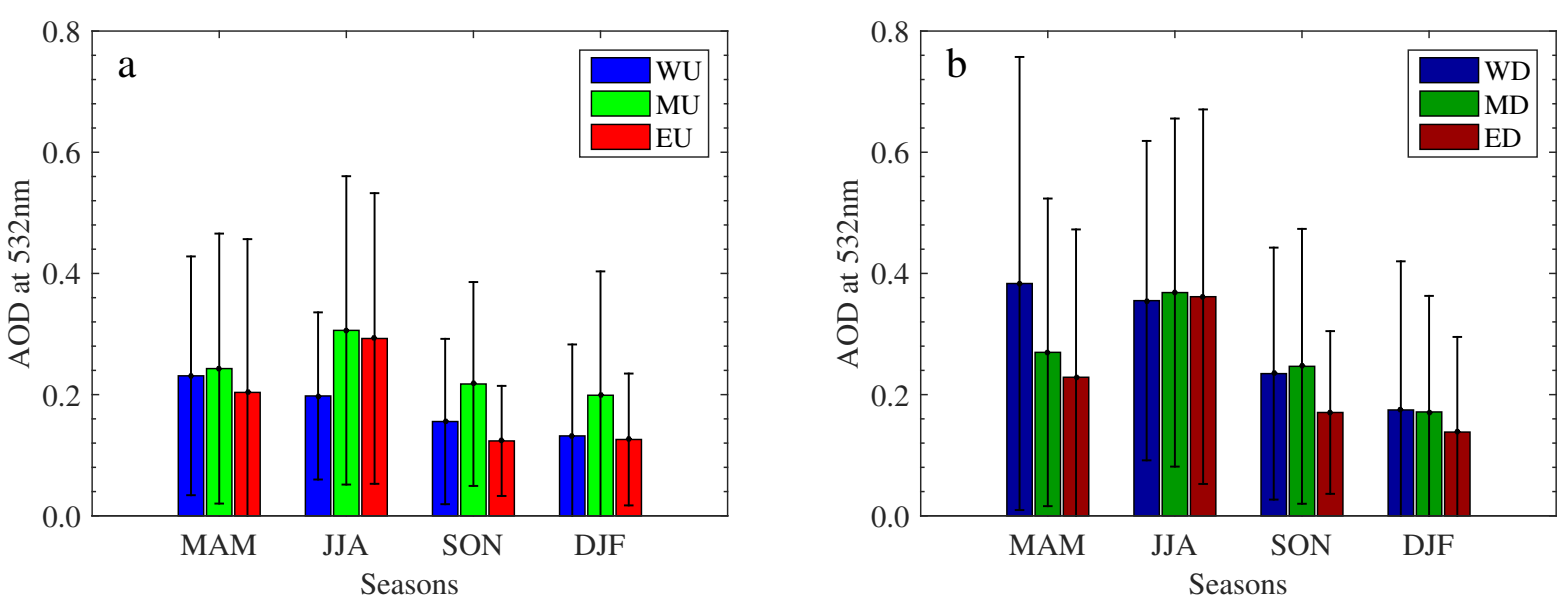

Figure 2. Seasonal variation of AOD at $532 \mathrm{~nm}$ for a) WU, MU and EU b) WD, MD and ED regions during June 2006 to December 2017.

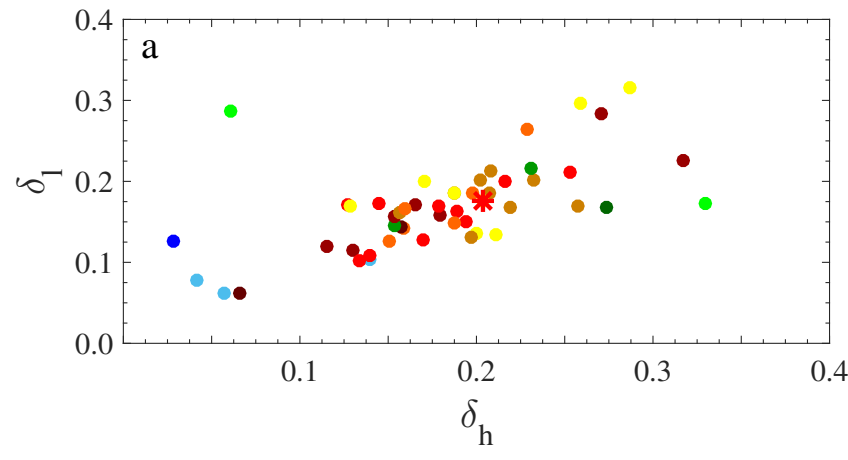

Dec Jan Feb Mar Apr May Jun Jul Aug Sep Oct Nov

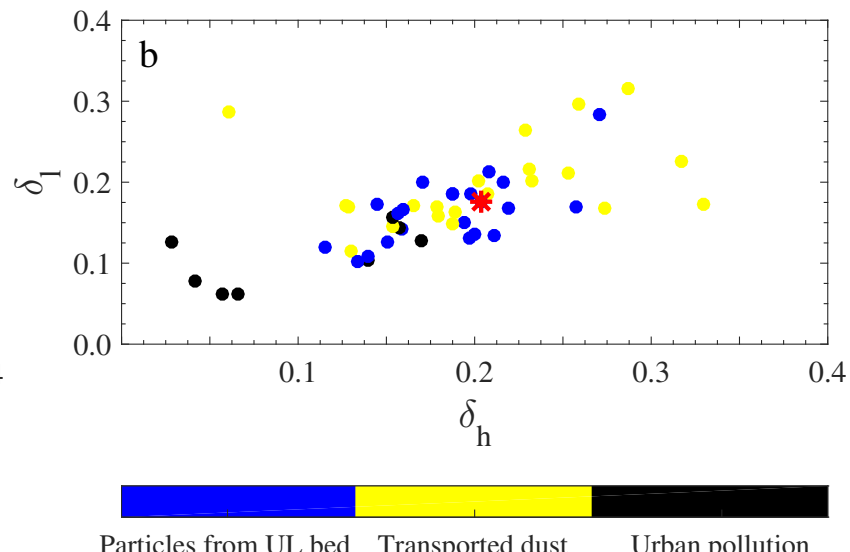

Particles from UL bed Transported dust Urban pollution

Figure 3. Variations of $\delta_{1}$ versus $\delta_{\mathrm{h}}$, a) happened at different months of the year, b) depending on the type of the atmospheric particles. $(*)$ corresponds to time series in Fig. 4.

also shown by a red asterisk (*) in Figs. 3a and 3b. It shows a dust layer that is in contact with the lake bed in MU region. The 48-hour HYSPLIT backward trajectories in Fig. 5 are indicating for a stable atmosphere in the vicinity of the surface at the time of this event. For this case, $\delta_{1}$ $\left(\delta_{\mathrm{h}}\right)$ is obtained as $0.18(0.20)$. The back trajectory that is starting at $3.5 \mathrm{~km}$ amsl shows that the dust layer which is extended up to $4 \mathrm{~km}$ may originated from the Syrian desert and north of the Mesopotamian region.

\section{Conclusion}

Referring to the recorded data on CALIPSO satellite we have found that the Urmia Lake in Northwest Iran has the potential to load salt particles into the atmosphere mostly in dry months of the year, June to October. The strength of this source is much lower than intense and widespread neighboring sources like the Mesopotamian region. Therefore it is not possible to distinguish clearly between particles which are originating from the lake and polluted dust particles which are transported from the neighboring

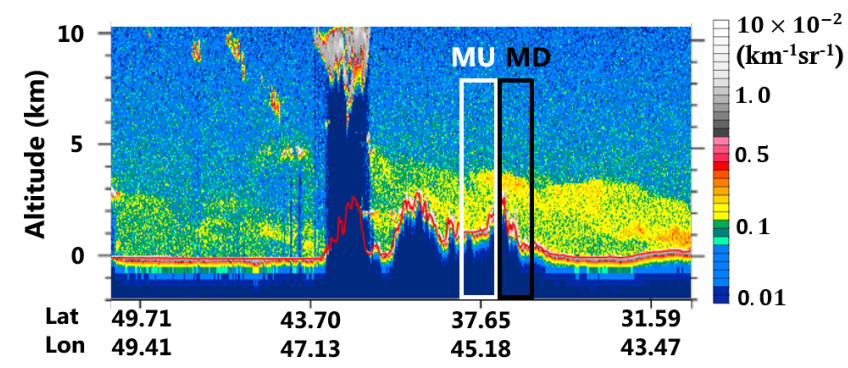

Figure 4. Total attenuated backscatter profile of CALIPSO's lidar at $532 \mathrm{~nm}$ around 23:00 UTC on 27 June 2017.

sources. Referring to few cases from CALIPSO time series where the aerosol layer is in contact with the lake bed, we have concluded that the particulate depolarization ratios $\left(\delta_{1}\right)$ for these particles are $0.16 \pm 0.05$ which are in agreement with corresponding reported values for dry salt particles [18]. We also believe that the CALIPSO algorithm can't detect such salt particles and for many cases, 


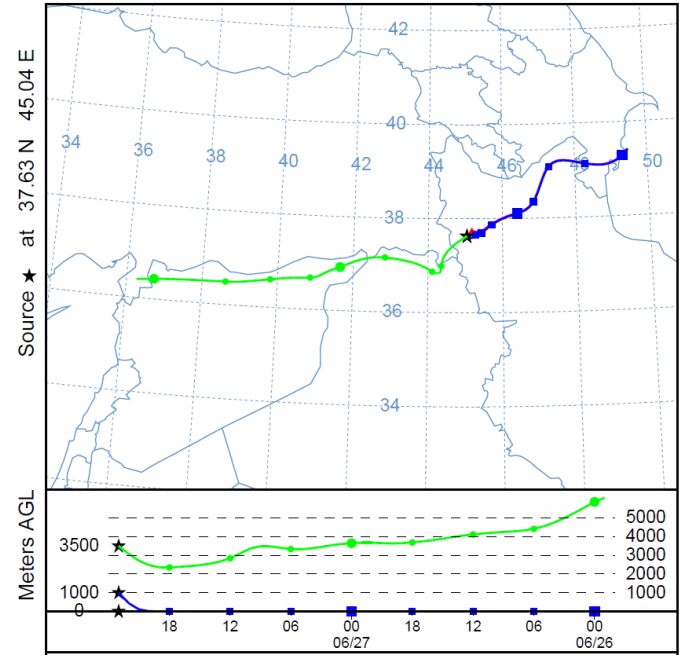

Figure 5. HYSPLIT-derived $48 \mathrm{~h}$ backward trajectories ending in the middle of the MU segment at 2300 UTC on 27 June 2017 at three levels 0,1 and $3.5 \mathrm{~km}$ above the ground level (AGL).

they are reported as polluted dust. To confirm these results, ground-based measurements are required. For the moment our team is preparing for them, but still we don't have trustworthy results to be reported.

\section{Acknowledgement}

The authors would like to acknowledge to NASA Langley Research Center for providing the CALIPSO data. Also, we are grateful to the NOAA Air Resources Laboratory (ARL) for the provision of the HYSPLIT transport model. We also would like to express our gratitude to Rouhollah Moradhaseli for valuable discussions.

\section{References}

[1] M. Zarghami, Lake and Reservoir Management 27, 87 (2011)

[2] B. Feizizadeh, T. Blaschke, Natural hazards 65, 2105 (2013)

[3] A. AghaKouchak, H. Norouzi, K. Madani, A. Mirchi, M. Azarderakhsh, A. Nazemi, N. Nasrollahi, A. Farahmand, A. Mehran, E. Hasanzadeh, Journal of Great Lakes Research 41, 307 (2015)
[4] M. Abbaspour, A. Javid, S. Mirbagheri, F.A. Givi, P. Moghimi, International Journal of Environmental Science and Technology 9, 257 (2012)

[5] A. Delju, A. Ceylan, E. Piguet, M. Rebetez, Theoretical and applied climatology 111, 285 (2013)

[6] A. Taravat, M. Rajaei, I. Emadodin, H. Hasheminejad, R. Mousavian, E. Biniyaz, Water 8, 478 (2016)

[7] F. Fathian, S. Morid, E. Kahya, Theoretical and Applied Climatology 119, 443 (2015)

[8] E. Hassanzadeh, M. Zarghami, Y. Hassanzadeh, Water Resources Management 26, 129 (2012)

[9] P. Ginoux, J.M. Prospero, T.E. Gill, N.C. Hsu, M. Zhao, Reviews of Geophysics 50 (2012)

[10] F. Abdi Vishkaee, C. Flamant, J. Cuesta, P. Flamant, H.R. Khalesifard, Journal of Geophysical Research: Atmospheres 116 (2011)

[11] F. Abdi Vishkaee, C. Flamant, J. Cuesta, L. Oolman, P. Flamant, H.R. Khalesifard, Journal of Geophysical Research: Atmospheres 117 (2012)

[12] A. Masoumi, H. Khalesifard, A. Bayat, R. Moradhaseli, Atmospheric research 120, 343 (2013)

[13] A. Bayat, H. Khalesifard, A. Masoumi, Atmospheric Measurement Techniques 6, 2659 (2013)

[14] S. Young, J. Atmos. Oceanic Technol 26, 1105 (2009)

[15] M. Tesche, A. Ansmann, D. Müller, D. Althausen, R. Engelmann, V. Freudenthaler, S. Groß, Journal of Geophysical Research: Atmospheres 114 (2009)

[16] J.M. Prospero, P. Ginoux, O. Torres, S.E. Nicholson, T.E. Gill, Reviews of geophysics 40, 2 (2002)

[17] V. Freudenthaler, M. Esselborn, M. Wiegner, B. Heese, M. Tesche, A. Ansmann, D. Müller, D. Althausen, M. Wirth, A. Fix et al., Tellus B: Chemical and Physical Meteorology 61, 165 (2009)

[18] M. Haarig, A. Ansmann, J. Gasteiger, K. Kandler, D. Althausen, H. Baars, M. Radenz, D.A. Farrell, Atmospheric Chemistry and Physics 17, 14199 (2017)

[19] A.H. Omar, D.M. Winker, M.A. Vaughan, Y. Hu, C.R. Trepte, R.A. Ferrare, K.P. Lee, C.A. Hostetler, C. Kittaka, R.R. Rogers et al., Journal of Atmospheric and Oceanic Technology 26, 1994 (2009)

[20] S. Burton, R. Ferrare, C. Hostetler, J. Hair, R. Rogers, M. Obland, C. Butler, A. Cook, D. Harper, K. Froyd, Atmospheric Measurement Techniques 5, 73 (2012) 